\title{
A Forest in Transition: the Role of Small-scale Disturbances
}

\author{
Kira Michelle Hoffman, Carley Coccola, \\ Kimberly House, and Annie Markvoort
}

\begin{abstract}
Large and small scale natural disturbances shape and define characteristics of forest stands. This research examines the response of a western hemlock stand following small-scale gapproducing events in Glacier National Park, British Columbia. The study used a megaplot with three individual quadrats to analyze dendrochronological, tree mensuration, vegetation and soil profile data. Results confirmed that three distinct age classes (new gap, intermediate gap, mature forest) were present, and that growth releases in dominant and sub-dominant trees corresponded with probable gap formation events. Productivity increased in new gaps and stand dynamics varied greatly in new- and intermediate- aged gaps. The dominant regeneration of western hemlock species on coarse woody debris is supported by small-scale disturbances, creating transitional forests in Glacier National Park.
\end{abstract}

Key Words: Gap dynamics, disturbances, mensuration, dendrochronology, British Columbia, Glacier National Park

\section{Introduction}

An ecological disturbance is characterized by a temporary shift in equilibrium, resulting in a pronounced change in an ecological system (Krebs, 1999). The forests of Glacier National Park experience several types of natural and anthropogenic disturbances that differ in scale, intensity, and frequency. Ecological disturbance research spans several academic disciplines varying from meteorologists studying weather patterns to entomologists focusing on insect outbreaks. Weather events, such as lightning and heavy snowfalls, cause avalanches and forest fires, which regularly damage entire forest stands (Johnson, Fryer \& Heathcott, 1990). Forest pathology research has shown that western hemlock looper and western balsam bark beetle cause significant damage and inhibit growth within Interior Cedar-Hemlock (ICH) forests (Bleiker, Lindgren, \& Maclauchlan, 2003; McCloskey, Daniels \& McLean, 2009; Parks Canada, 2009). Forest disturbances are dynamic and there are often several contributing factors leading to a change in an ecological system. 
Understanding ecological disturbances requires an interdisciplinary research approach.

Ecological disturbances are also central to archeological research because anthropogenic disturbances contribute to changes in the landscape at a variety of scales. In Glacier National Park First Nations including the Secwepemc, Okanagan, and Ktunaxa people traditionally used the land for seasonal hunting and foraging (McCleave, 2008). Since the arrival of western settlers, significant anthropogenic alterations of the landscape have occurred, such as the construction of the Canadian Pacific Railway through Rogers Pass and the ongoing avalanche control along the highway corridor (Downs, 1980). Regardless of the cause of disturbance, forest regeneration is often inhibited by intense snow pack and brush-dominated species like slide alder (Alnus) or thimbleberry (Rubus parviflorus) (Parks Canada, 2009).

Although large-scale disturbances have dramatic effects on forest stands, small-scale disturbances, such as those producing gaps in the forest canopy, can have greater overall effects on forest health (Spies, Franklin \& Klopsch, 1990). Small canopy gaps, or forest gaps, are an important factor in disturbance regimes and vegetation growth (Duncan, Buckley, Urlich, Stewart \& Geritzlehner, 1998; Scharenbroch \& Bockheim, 2007). Forest gaps characterize a disturbance where a singular dominant tree dies or loses a branch, creating small openings in the forest canopy (McCarthy, 2001). Dominant trees are often the tallest and oldest trees in a stand. These trees are often partially decayed and the first to be affected by severe weather events (Coates, 2000). It is predicted that incidents of severe weather, insect outbreaks, and forest fire activity will increase with a warming climate. By studying current disturbance dynamics in forest ecosystems, researchers can better understand how forests will respond to disturbances in the future.

Gaps naturally occur in old growth and mature forests and are an indicator of overall forest health (Yamamoto, 2000). Researchers use gap dynamics to study the rate and type of species regeneration associated with single-tree disturbances (Runkle, 1992). The theory of gap dynamics proposes that canopy gaps provide increased solar radiation, higher soil temperatures, and soil moisture, creating microclimates that favour shade-intolerant species (Gray \& Spies, 1997; Scharenbroch \& Bockheim, 2007; Yamamoto, 2000). The balance between increased sunlight, shade from stumps and coarse woody debris (CWD) enhances seedling survival (Gray \& Spies, 1997). CWD allows for recruitment of western hemlock seedlings, which out-compete other species due to their ability to germinate in a litter mostly void of mosses (Peterson, Peterson, Weetman \& Martin, 1997). These optimal growing conditions increase species richness, defined as the number of different species within a given area (Peterson et al., 1997; Siitonen, 
Martikainen, Punttila \& Rauh, 2000). Gaps in the canopy cover affect species composition, succession, nutrient cycles, and habitat structure (Spies et al., 1990). Forest gap dynamics have been predominantly studied in tropical and temperate hardwood forests and to a lesser extent in western Canadian coniferous forests (Spies et al., 1990; Bartemucci, Coates, Harper \& Wright, 2002).

\section{Research Hypothesis and Objectives}

This research represents the first gap dynamics study completed in Glacier National Park. This research is important because small-scale disturbances are indicators of overall forest health. Forest gaps provide a window into the future, where researchers can define the rate and type of species that will colonize a forest as it responds to change. The purpose of this research is to examine whether small-scale disturbances regulate species replacement patterns and support increased species richness and productivity in Glacier National Park. It is hypothesized that newer (more recent) small-scale disturbances create favourable site conditions, leading to increased species richness and productivity due to the abundance of otherwise limiting growth factors such as sunlight, nutrients, and precipitation. The objectives of this research are twofold: (1) Describe small-scale disturbances using dendrochronological and ecological survey techniques supported by soil profile analysis to examine species replacement patterns; and (2) Discuss whether productivity and species richness increase or decrease as a gap matures.

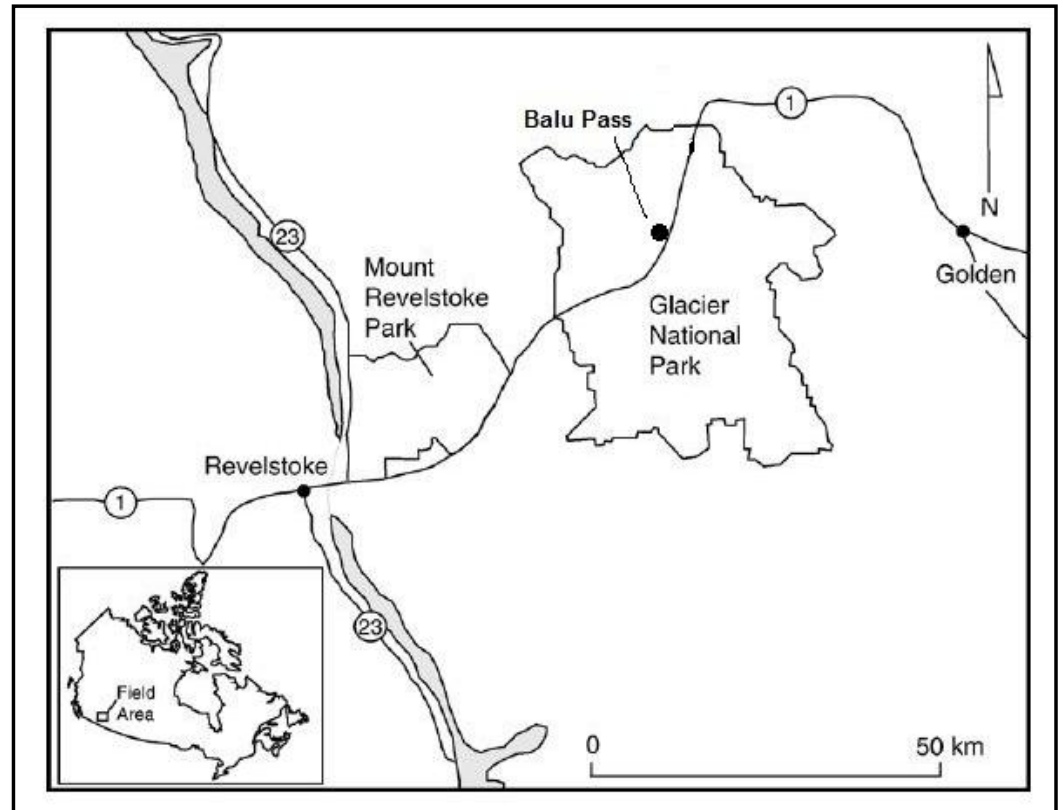

Figure 1: Location of the study area in Glacier National Park, B.C. 


\section{Study Area}

The study was conducted in Balu Pass, Glacier National Park in the Columbia Mountains of southeast British Columbia, Canada (Figure 1). Research was completed in September 2011 to allow for identification of herbaceous plants and sampling of trees with the most recent growth year present. The study area was chosen based on several factors, such as access to the site, forest age, tree species present, and elevation above sea level (asl). A megaplot was selected in the study area at $\mathrm{N} 51^{\circ} 18^{\prime} 01^{\prime \prime}, \mathrm{W} 117^{\circ} 31^{\prime} 26^{\prime \prime}$ approximately $1386 \mathrm{~m}$ asl. The megaplot had an east-facing aspect with slope gradients ranging from $24 \%$ to $61 \%$. According to British Columbia's ecosystem classification system, the megaplot was situated within the ICH biogeoclimatic zone with the sub-classification moist cool (mk1) (Figure 2), just below the elevation of Engelmann Spruce Sub-Alpine Fir (ESSF) zone (Ketcheson et al., 1991).

The climate in Glacier National Park is classified as interior continental, with cool, wet winters and warm, dry summers influenced by easterly flowing air masses (Johnson et al., 1990). These rising air masses cause expansion and cooling which result in high precipitation throughout the park. Mean annual precipitation is 1278 mm (Parks Canada, 2011) and average monthly temperatures range from -9 to +20 degrees Celsius (Parks Canada, 2009b). Within the megaplot, soils ranged from brunisolic to podzolic development, with an overall podzolic soil classification due to elevation and precipitation (Coates, 2002).

The ICH in Glacier National Park is an example of a productive forest with abundant tree species including: western hemlock (Tsuga heteophylla), mountain hemlock (Tsuga mertensiana), sitka spruce (Picea sitchensis), western red cedar (Thuja plicata), and sub-alpine fir (Abies lasiocarpa). Characteristic vegetation of the area includes devil's club (Oplopanax horridus), lady fern (Athyrium filixfemina), oak fern (Gymnocarpium dryopteris), rosy twistedstalk (Streptopus roseus), spiny wood fern (Dryopteris expansa), oval-leaved blueberry (Vaccinium ovalifolium), and black huckleberry (Vaccinium membranaceum) (Ketcheson et al., 1991; Pojar, MacKinnon, \& Coupe, 2008). 


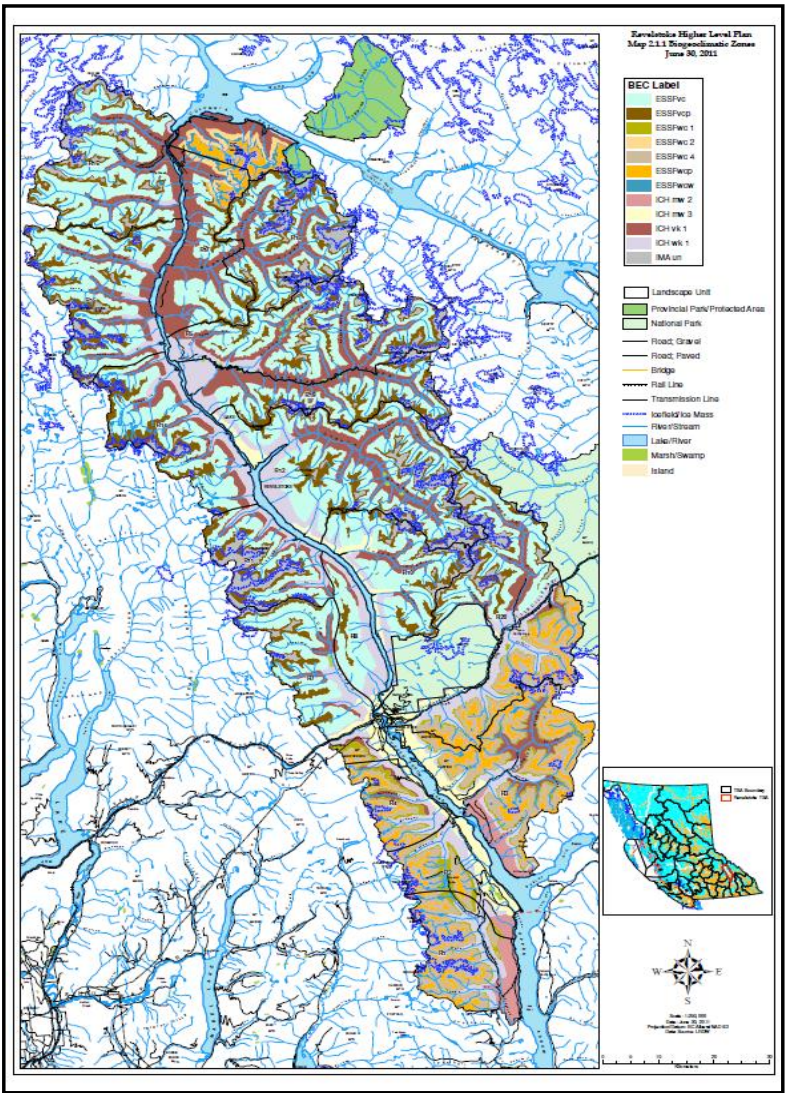

Figure 2: Location and distribution of Interior-Cedar Hemlock zone in British Columbia (Ministry of Forests, 2011).

\section{Methods}

Plot Selection

A large plot was chosen to obtain information on a wide range of herbaceous species growing in similar forest conditions (Clark \& Clark, 1992). A rectangular plot measuring $40 \mathrm{~m}$ x $15 \mathrm{~m}$ was established by determining a perimeter with a compass, measuring tape, and a hand-held Garmin GPS receiver. Tree density was estimated to ensure the megaplot contained a minimum of 20 trees, the sample depth appropriate for comparison of annual tree ring widths across a relatively homogenous stand (Cook \& Kairiukstis, 1992). The plot consisted of a single forest type with three distinct age classes. These age classes were delineated to create three distinct quadrats: quadrat one was classified as young, with an open canopy, quadrat two as mature, with a closed canopy, and quadrat three as an intermediate forest, with a closed sub-dominant canopy. A sketched map was created to log the plot perimeter, age class perimeters, and locations of significant CWD, soil pits, tree cores, and tree samples. 


\section{Vegetation Survey}

A complete species list of mosses, herbaceous, and shrubby plants was assembled within each of the three quadrats (Parish, Lloyd, Coupé \& Antos, 1996; Pojar et al., 2008). For each quadrat, the percent cover of mosses, herbs, and shrubs was recorded and percent canopy closure was estimated visually (Roush, 2007; BEC Field Manual, 1998). Within each of these layers, the percent cover of each individual species was estimated visually to the nearest $1 \%$, after two researchers averaged estimations throughout the quadrat. The vegetation data collected was used to demonstrate the qualitative differences between the three time series gaps. Visual representations of species richness (ground cover, herbaceous, shrub) among the three quadrats as well as percent cover by layer were created.

A survey of CWD, defined as fallen trees or branches, uprooted trees no longer living, and other wooden debris that are not self-supporting, was taken via a transect, which crossed through the three quadrats at the center of the megaplot. Diameter and decay class were recorded for each piece of CWD encountered along the transect with a diameter greater than $7.5 \mathrm{~cm}$ (BEC Field Manual, 1998). CWD decay classes were recorded on a scale of 1-5, with "6" added as an additional class for CWD that had undergone significant decay. To reduce the chance of bias in the results, two individuals estimated and compared classifications for each piece of CWD.

\section{Dendrochronology and Tree Mensuration}

Living tree cores and tree measurements were collected from the largest twenty trees in the megaplot. Trees were sampled radially at breast height $(\sim 1.3 \mathrm{~m})$ on the upper slope using a $5.2 \mathrm{~mm}$ increment borer. Diameter at breast height (DBH) was chosen because it is the standard measurement to avoid swelling of the basal tree butt and other growth distortions (Roush, 2007). One core was taken per tree, but in the instances of rot, two cores were taken to provide a greater sample depth. Cores were stored in plastic straws for transport to the University of Victoria Tree Ring Lab (UVTRL), where analysis was conducted.

Tree heights were acquired in meters using a Nikon range finder and these measurements assisted with the on-site classification of dominant and co-dominant canopy trees. Species type, overall tree health, and crown dimension were recorded to assess potential disturbances, such as fire scars and insect outbreaks (Roush, 2007). Seed trees $<5 \mathrm{~cm} \mathrm{DBH}$ and approximately $1 \mathrm{~m}$ in height were cut with a handsaw and cross-sections were taken for measurement in the UVTRL. Individual 
seedlings ( $<1 \mathrm{~cm} \mathrm{DBH}$ and $<1 \mathrm{~m}$ ) were tallied and their age determined on site by counting individual whorls.

To prepare for dendrochronological analysis, tree cores were air dried and then glued on to slotted mounting boards (Stokes \& Smiley, 1964). Cross-sections and mounted cores were sanded with progressively finer sandpaper to a 600 gritpolish (Stokes \& Smiley, 1964). The exact age of each sample was determined using a Velmex stage and Wild M3B microscope with $0.01 \mathrm{~mm}$ focusing power, coupled with a CCD video display. Exact-age dating was applied where possible to provide a complete picture of the establishment and mortality of trees in the plot (Gutsell \& Johnson, 2002). Correlation analysis was conducted using the statistics program IBM SPSS 20 to verify if there was a relationship between the dependent variables (DBH and height) and the independent variable (age), and to allow for the production of a simple model to predict age. Subsequent analyses were conducted to describe variations between quadrats.

\section{Soil Sampling}

Three soil pits were dug to approximately $60 \mathrm{~cm}$ in the center of each of the three quadrats and their locations were recorded with a hand-held Garmin GPS receiver. Soil horizon depths as well as fabric and litter layer thickness were measured with a measuring tape to millimeter accuracy. The biotic compositions of the litter layers were recorded to determine the presence of organics, mycelium abundance, and detrital activity. The percent composition of fine fragments (sand, clay, and silt) was estimated in each pit to determine the overall soil type using a soil texture triangle, which included a taste test, moist cast test, and graininess test (BEC Field Manual, 1998). The size and shape of the soil particles were classified and the resulting drainage properties of the soil were estimated. The deposition of the area was noted based on the surrounding site geomorphology. Soil samples containing gravels $<7$ $\mathrm{cm}$ from each pit were collected in petri dishes for examination. Samples were taken from each horizon, dried, and then classified using a Munsell color chart (BEC Field Manual, 1998).

\section{Results}

Vegetation and Course Woody Debris

The percent cover within each of the three structural vegetation layers (ground cover, herbaceous, shrub) was highest in quadrat one (Figure 3). Quadrat two had lower percent cover in each layer, and quadrat three had the lowest overall percent cover. These results were consistent with the percent canopy closure of dominant and sub-dominant trees within each quadrat (Figure 4). Quadrat one, the youngest 
gap, consisted of two dominant trees resulting in a $10 \%$ canopy closure. This contributed to the high percent cover of understory species observed (Figure 3). Quadrat two, the mature living forest had 85\% canopy closure with low understory species biomass. Quadrat three, the intermediate gap, had a very dense subdominant tree layer, which coincided with the lowest percent cover of understory biomass. Here, the distribution of western hemlock and mountain hemlock resulted in a canopy closure of $95 \%$.

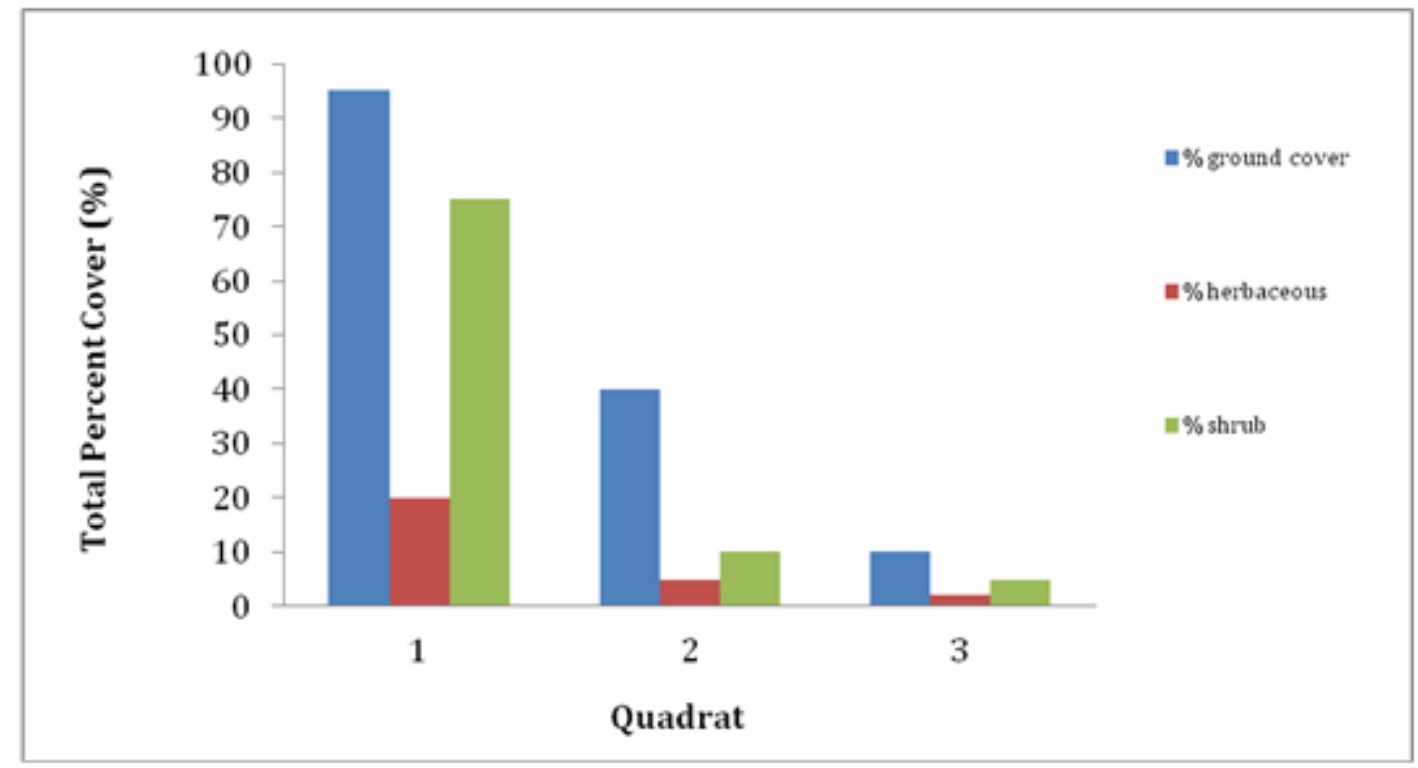

Figure 3: Percent cover in each vegetation layer in the three surveyed quadrats. 


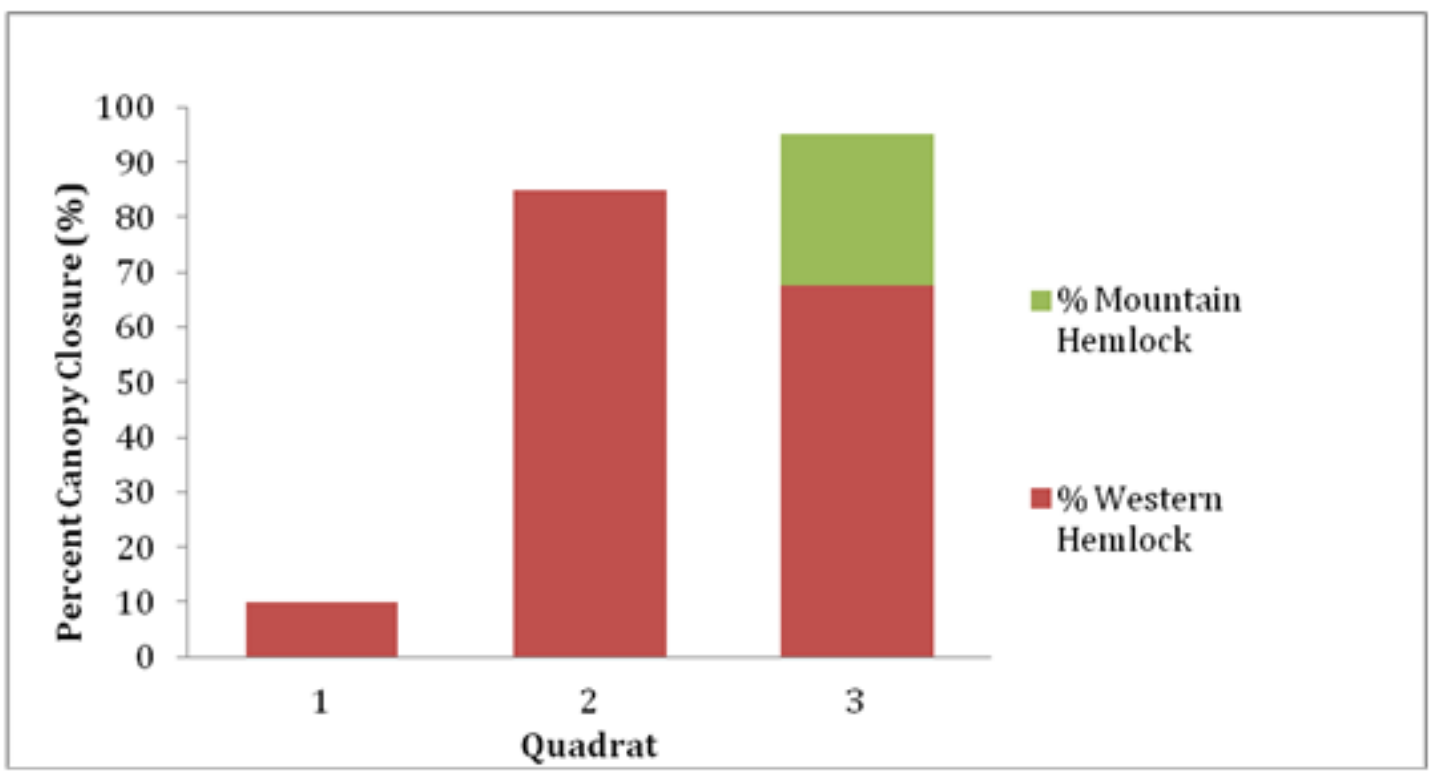

Figure 4: Percent canopy closure of dominant and sub-dominant trees in the three surveyed quadrats.

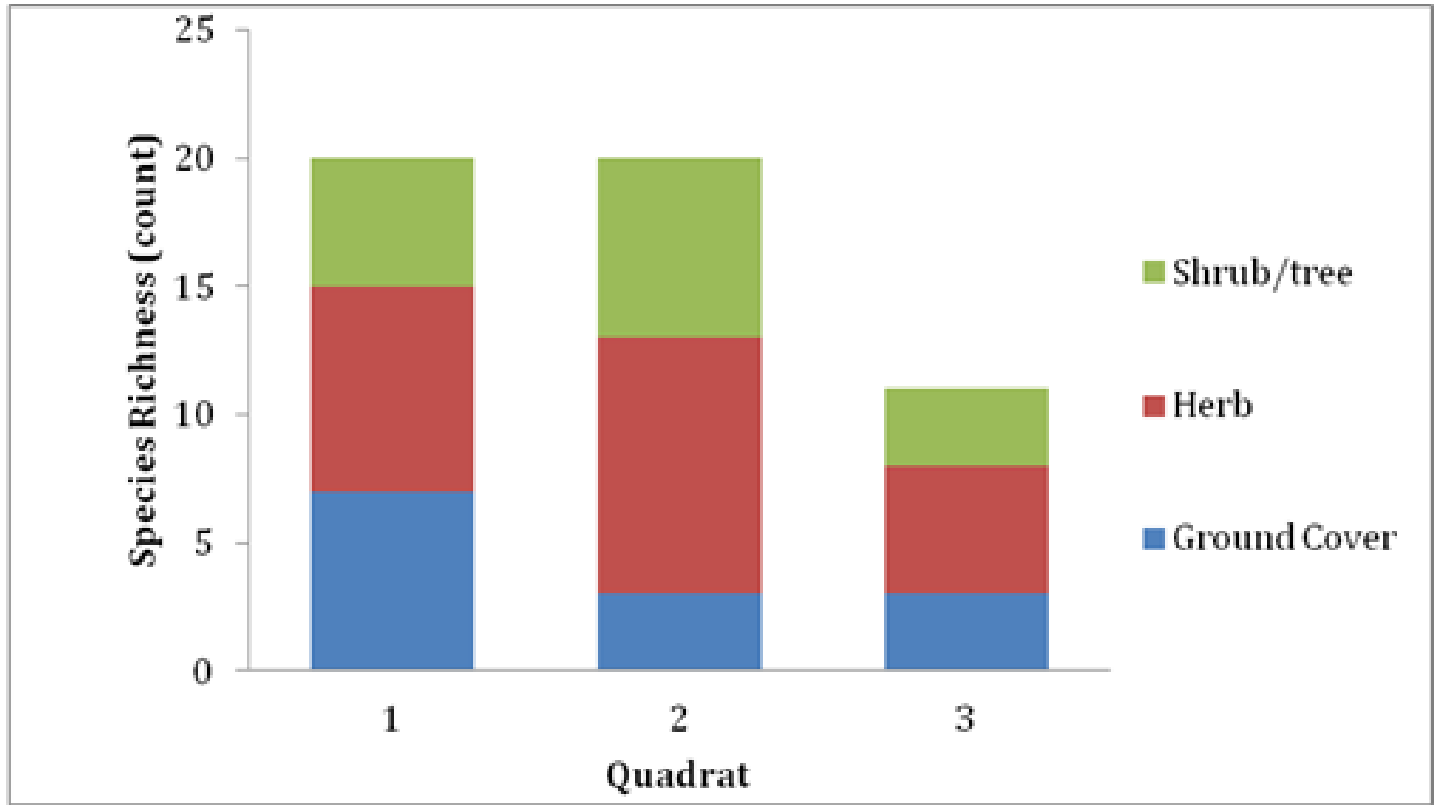

Figure 5: Species richness of ground cover, herbaceous and shrub layer is the three surveyed quadrats. 
Species richness varied among the three quadrats (Figure 5). Quadrats one and two had the same overall species richness although a higher number of mosses were growing in quadrat one. It should be noted that although species richness was similar between these two areas, richness reflects absolute counts of species and not percent cover. Percent cover was higher in quadrat one (Figure 3). In quadrat three, species richness was lower in all sub-canopy layers. This coincided with the high canopy closure of sub-dominant and dominant trees.

The volume, size, and decay of CWD varied greatly along the transect (Figure 6). The first $15 \mathrm{~m}$ of the transect were within quadrat one, where a high volume of CWD existed. From 15 to $27 \mathrm{~m}$, the transect passed through quadrat two where several large, standing hemlock trees resulted in very little CWD. From 27 to $40 \mathrm{~m}$, the transect passed through quadrat three where a dense stand of small hemlock trees was growing. Here, the volume of CWD increased again; however, this increase was noted in decay classes five and six. Some of the CWD in this quadrat was severely decayed and could not be recorded in the CWD transect results.

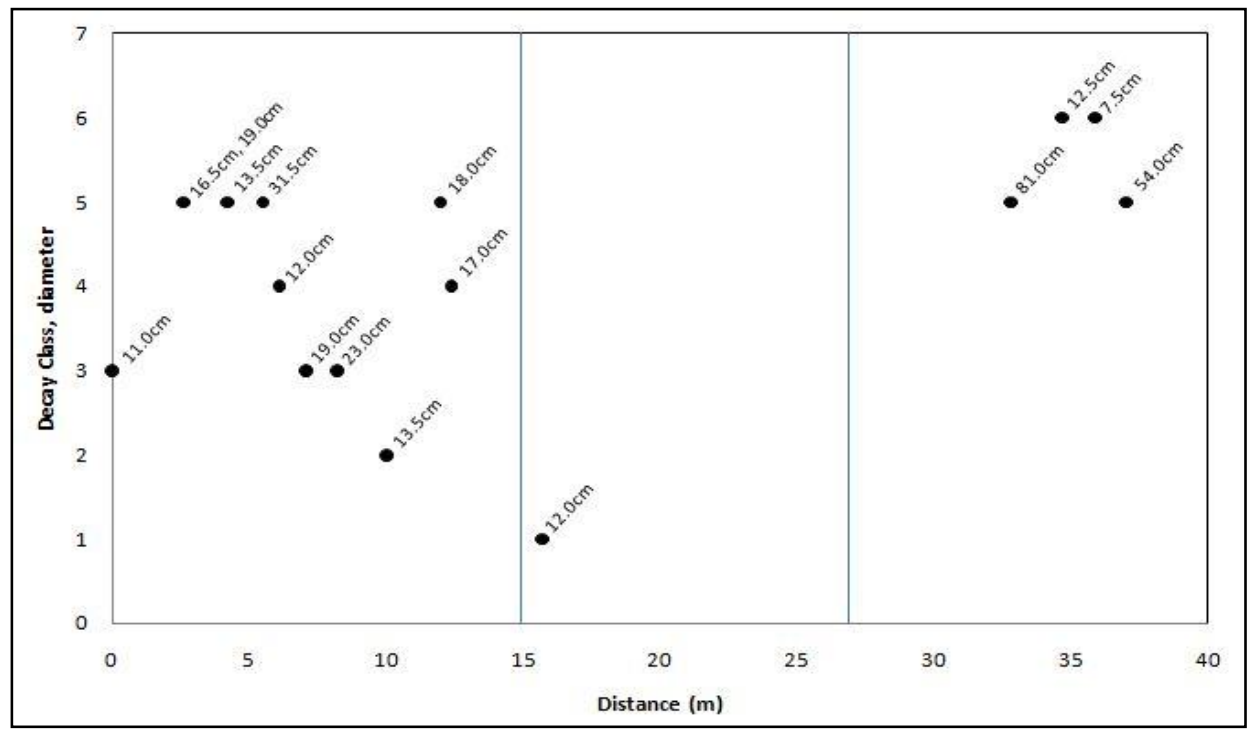

Figure 6: Coarse woody debris transect.

\section{Dendrochronology and Tree Mensuration}

The final chronology of the plot extended 270 years with the sample age uniformly distributed. Pith was achieved for most of the trees in the survey area, but exact ages remained unknown where rot was encountered. Based on statistical analysis, Pearson's correlation (R) was 0.948 between the DBH and age and 0.932 between 
height and age. Due to this strong relationship, DBH and height were plotted against age and a least squares regression was applied (Figure 7 and 8 respectively) to determine whether age explained either of the dependent variables. The coefficient of determination $\left(\mathrm{R}^{2}\right)$ for height as a function of age was 0.868 , whereas the $\mathrm{R}^{2}$ value for DBH as a function of age was 0.898 .

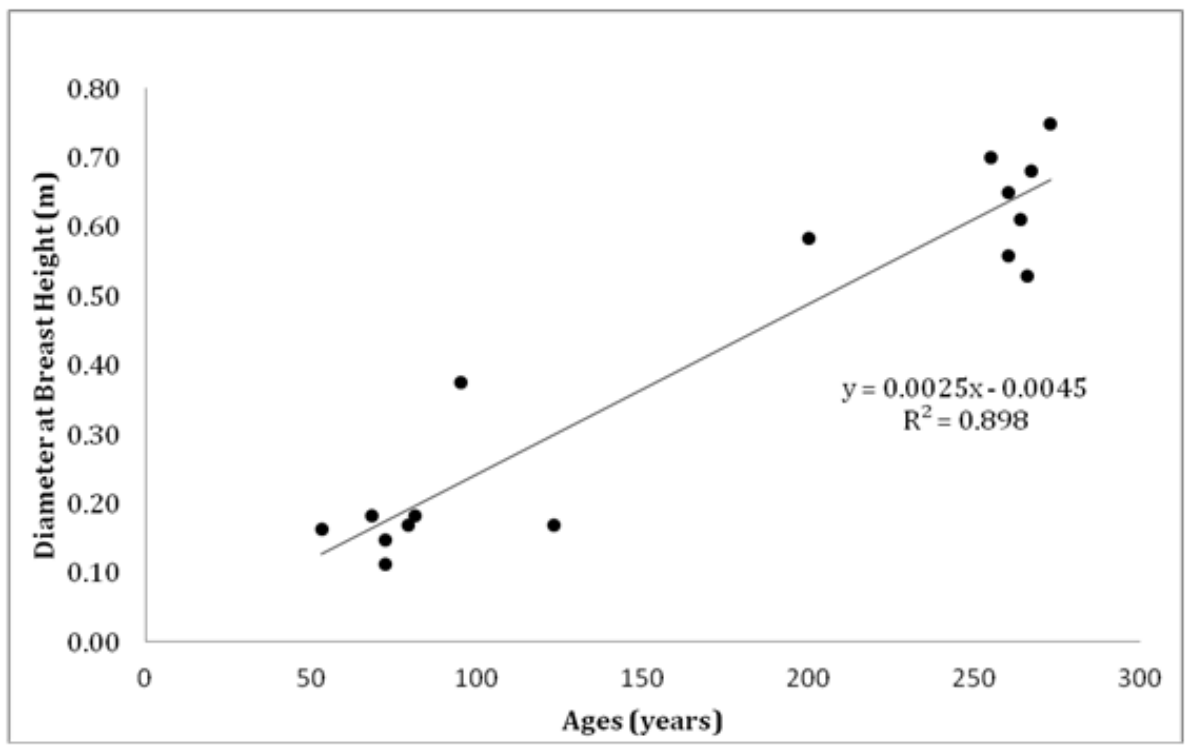

Figure 7: DBH of mensurated trees in megaplot as a function of tree age.

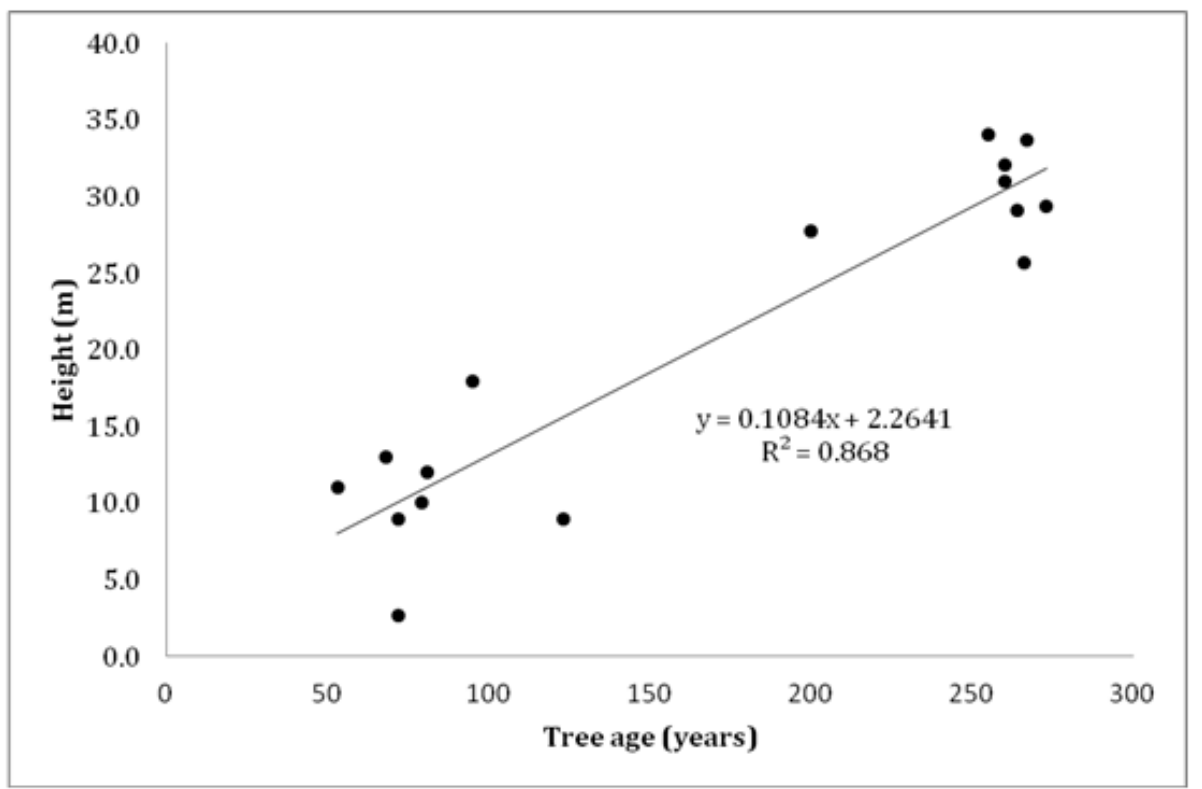

Figure 8: Height of mensurated trees in megaplot as a function of tree age. 
As a result, age was concluded to have a stronger relative strength index with DBH than with height (McGrew \& Monrow, 2000). Therefore, the model produced for the linear relationship of tree age and DBH was used to extrapolate estimated ages for trees where pith (the center of the tree) was not achieved. The known and estimated ages were then plotted per quadrat to give an average representation of western hemlock species within the survey area (Figure 9).

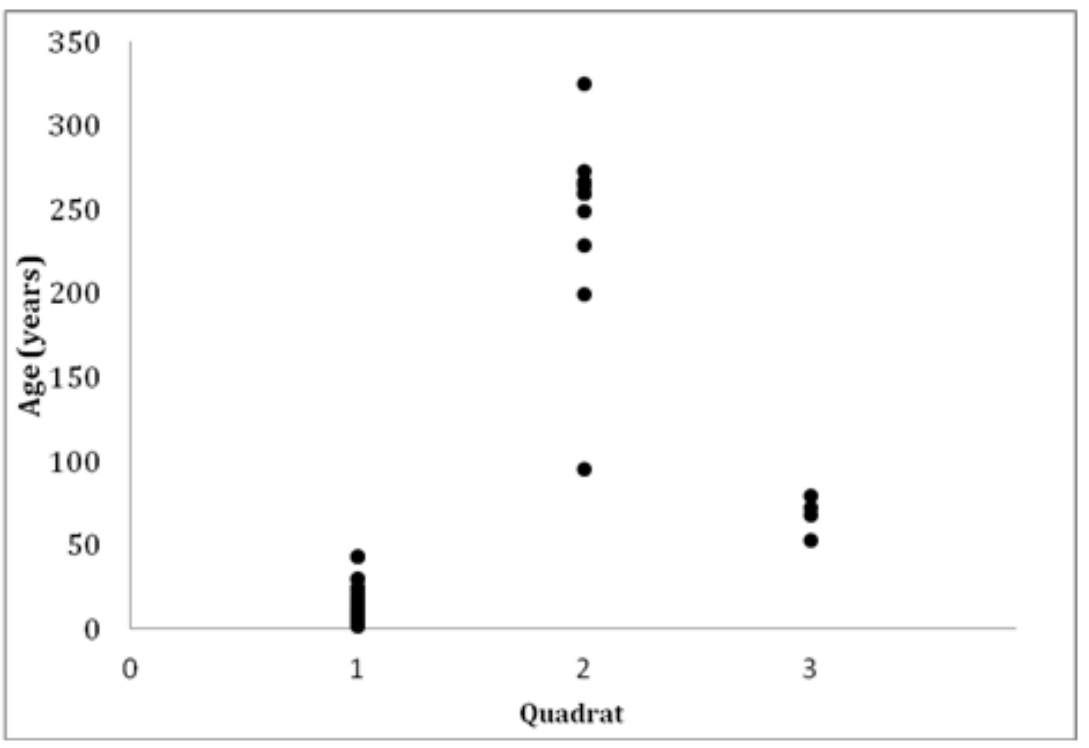

Figure 9: Average representative age of western hemlock trees per quadrat.

Each individual core was visually cross-dated to assess and compare growth release rings (a large productive growth ring bounded by smaller constrained growth rings) surrounding the gap formations. Dendrochronological analysis resulted in an average age class per quadrat allowing for the examination of relationships within gaps. A period of good growth throughout the megaplot was observed between approximately 1950 and 1960 AD. This growth did not correspond with any known gap formations and was likely the result of favourable climatic conditions in the region. However, consistent periods of good growth years in trees surrounding gaps are suspected to be the result of the mortality of a dominant tree (Speers, 2010). These growth results are specified below with respect to each quadrat.

\section{Quadrat One}

Only two large trees were found within quadrat one as the rest of the quadrat consisted of an open forest gap comprised of ground cover species, herbaceous plants, shrubs, and hemlock seedlings. The average age throughout the open gap 
area was 11.9 years with a standard deviation of 10.5 years. Good growth conditions were observed in the dominant trees in the gap from approximately 1980-1985 AD, corresponding to the probable time of seedling germination in the center of the gap. Within the time periods 1940-1945 AD and 1920-1925 AD, trees surrounding the gap demonstrated distinct growth releases, likely coinciding with the time of the disturbance forming the gap.

The age of the oldest sapling in quadrat one was 43 years and is likely one of the first individuals to have re-colonized the gap following the disturbance. The three larger saplings in the gap were identified as western hemlock and found on the perimeter of the open area. The age of saplings and seedlings ranged considerably within the quadrat, and overall western hemlock productivity was high. For example, on a single nursing log, 209 live one-year old hemlock seedlings were counted. The age distribution of regenerating hemlock seedlings was plotted to show the variability in the population (Figure 10).

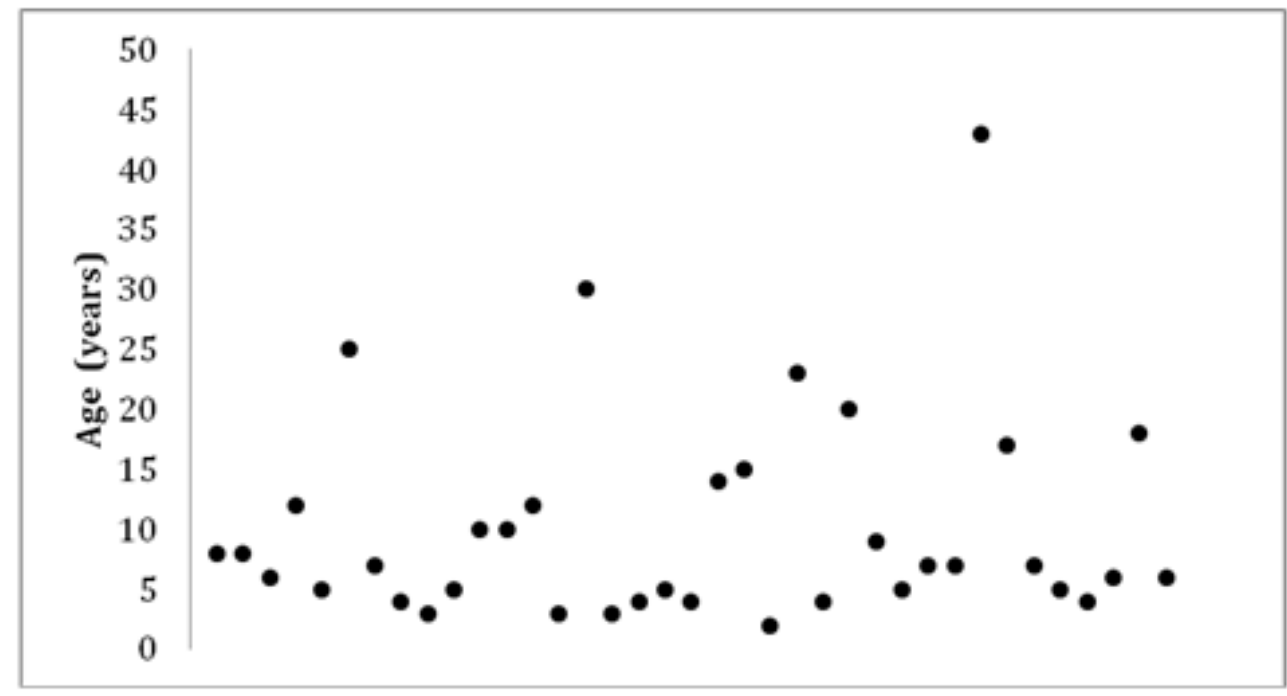

Figure 10: Age distribution of regenerating hemlock seedlings in quadrat one.

\section{Quadrat Two}

The trees in quadrat two were the oldest in the megaplot, with an average age of 216 years (Figure 9). Dendrochronological results showed no overarching growth correlations among the total population of quadrat two. However, growth release patterns in several trees of quadrat two corresponded to the estimated age of the gaps in quadrats one and three. 


\section{Quadrat Three}

The trees in quadrat three were an evenly aged distribution of western hemlock and mountain hemlock species, with only $67.3 \%$ living (33) and $32.7 \%$ (16) dead. The height of the living trees plotted against DBH had a linear correlation with a Pearson's R value of 0.787 (Figure 11).

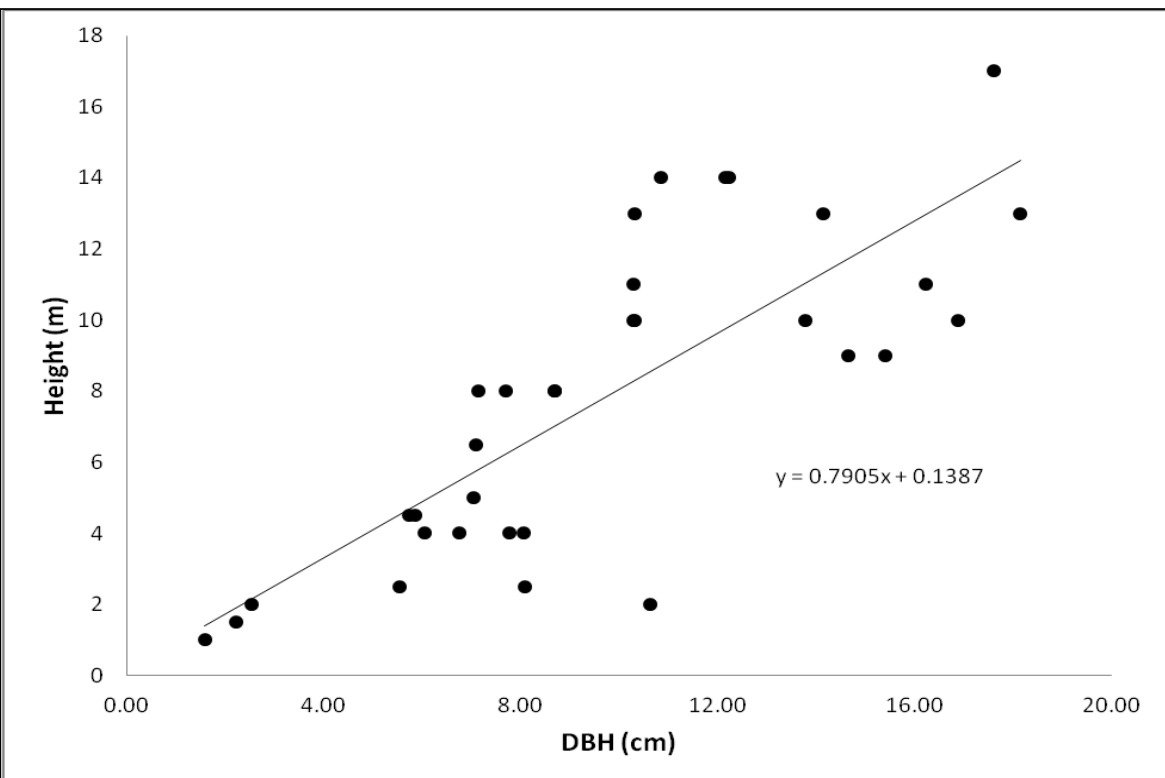

Figure 11: Height as a function of DBH for western and mountain hemlock species in quadrat three.

Our results point to two disturbances that affected growth in quadrat three over approximately 120 years, as was evident in the growth releases of several older trees (approximately 200 years) surrounding quadrat three. These trees demonstrated growth releases between 1930-1940 AD, corresponding to the average age of living, juvenile trees populating this intermediate gap. The average age of the living trees was 68 years, with a standard deviation of 11 years. The 200 -year-old trees also demonstrated a growth release approximately 1890-1900 AD, which may have resulted from a small-scale disturbance event. The gap in quadrat three is distinctive from the gap found in quadrat one due to the older average stand age, higher density of trees, and higher rate of mortality.

\section{Soil Results}

Soils in quadrat one were classified as a silty loam and soils in quadrats two and three were classified as fine sandy loams. These classifications were derived from 
the percent of fine fragments. Although overall soil types in each quadrat were similar, substantial differences in the litter and fabric layers as well as the A horizons existed between soil profiles. Fine fragments were classified as sands, silts or clays. Course fragments (>2 mm) were classified as sub-angular in each pit and were relatively uniform in abundance. Sites were classified with a colluvium deposition based on the slope and surrounding geomorphology.

Soil pit one had no litter layer but a fabric layer of $2.3 \mathrm{~cm}$ depth. The colour of the humus layer indicated there was a high level of organic material present. The A horizon was strongly leached into the lower horizons creating a distinctly white appearance. This soil pit was classified as a well-drained podzolic silty loam based on the presence of fine fragments, biotic component, and colour.

Soil pit two also had no distinguishable litter layer and had the smallest observed fabric layer of $1.9 \mathrm{~cm}$ depth. There was a trace of an organic layer present directly above the A layer and below the humus layer. There were two A horizons identified in the pit, both of which were less leached than pit one, resulting in a more pinkish appearance. This soil pit was classified as a well-drained podzolic fine sandy loam based on the greater percent of fine fragments, biotic component, and lighter colour.

Soil pit three was the only pit that had a distinct litter layer. This litter layer was significant and measured to $5.0 \mathrm{~cm}$ in depth. Pit three also contained the largest fabric layer at $3.0 \mathrm{~cm}$, with significant amounts of consolidated matted mycelium matter. Beneath the trace humus layer, two leached A horizons were present. Leaching was not as obvious as in pit one, leaving the soil with a pinkish-grey appearance. This soil pit was classified as a well-drained podzolic fine sandy loam based on the greater percent of fine fragments and biotic component.

\section{Discussion}

Dendrochronological and forest mensuration results from the three quadrats within the megaplot describe four distinct disturbances over a period of approximately 120130 years. These disturbances are likely the result of separate single, dominant-tree mortality events, which is evident due to the abundance and decomposition of CWD in the gap areas of quadrats one and three. Our study site presented an opportunity to examine three distinct and diverse age classes and their representative microclimates occurring within a condensed setting. Our results were consistent with our hypothesis that newly formed gaps and notably that small-scale disturbances create favourable conditions for increased species richness and productivity. These new gaps also regulate species replacement patterns and create transitional forests. It is important to note that in the intermediate gap, species 
richness and productivity were very low, but that in the mature gap species richness was comparable with the newly formed gap. This finding demonstrates how equilibrium shifts create dynamic and transitional forests and how important disturbances are to forest health and biodiversity.

Increased canopy heterogeneity suggests that the forest is transitioning from a mature to an old growth stage. This is further supported by the presence of several large veteran trees, snags, CWD, and various stages of successional regrowth (BEC manual, 1998). In areas like Glacier National Park, which have a high frequency of large-scale disturbances, small-scale disturbances like those in this study may provide a niche for the future species composition of the forest (Sherman, Fahey \& Battles, 2000).

The three quadrats in the megaplot are examples of an ICH forest in three distinct age classes. Quadrat one in the megaplot represents the youngest age class in the study. Formed likely by a single disturbance event, quadrat one had all the characteristics of a traditional forest gap, containing high amounts of herbaceous and shrub species, as well as CWD in the form of nurse logs (Peterson et al., 1997). Here, a significant amount of partially decomposed CWD provided the basis for new generations of western hemlock trees. In this quadrat, a single remaining veteran in the southwest corner of the quadrat, which offered only $10 \%$ canopy closure, provided the shade required to support secondary succession in the gap. The average age of juvenile trees in the quadrat was approximately 11 years. This, along with the presence of more than 200 new seedlings, supported quadrat one as the youngest age class in the megaplot.

As an intermediate age class, quadrat three demonstrated a more progressed stage of hemlock gap colonization. The deep litter and fabric layers, coupled with stage six decomposition of CWD confirmed that quadrat three is a gap, which likely formed following the fall of a veteran tree. The amount and density of trees within this small quadrat (more than 30) with a relatively even age of about 70 years, suggest that this quadrat was a mature gap with an intermediate age class. Seedlings likely germinated following the formation of a gap and subsequently out-competed each other for light and nutrients.

Quadrat two, in the center of the megaplot, was the oldest age class in the study area, with several evenly-spaced large western hemlock trees spanning the quadrat. Although many of the trees experienced some form of damage, there was no evidence of constant stress as evident in tight ring widths among the stand. The limited amount of CWD indicated an absence of small-scale disturbance events. A very thin fabric and litter layer in conjunction with an $85 \%$ closed canopy substantially reduced the percent cover of species in the understory. The trees in 
quadrat two are an example of a successional stand that is too large to be formed by a small, single disturbance event. The consistent age of the stand (with all samples approximately 200 years or older) was likely established following a large-scale disturbance.

Although it was hypothesized that species richness would increase with the formation of a new gap, our results show that the overall species richness in our young gap did not differ from species richness in the stable stand (quadrat two). These findings indicate that either there is no increase in species richness with the formation of a gap, or that the spatial autocorrelation between quadrat one and quadrat two caused species richness to be constant. However, in comparing the two gaps, it was found that species richness in the young gap (quadrat one) was much higher than richness in the intermediate gap (quadrat three). Despite the species richness findings, substantial differences in productivity between the three quadrats were observed.

The plant community found in quadrat one represented species that are "gap requiring," made evident by the fact that they were present in high percentages in the gap (Acevedo, Urban \& Ablan, 1995). Microclimatic elements such as sunlight availability, increased precipitation, soil temperature, substrate, organic matter, and edge effects (precipitation drip line) also influenced the type and abundance of plants in the early successional gap community. Soil pits were initially introduced in the study to compare potential differences between "gap requiring" species and shade tolerant species, as well as their respective underlying substrates (Wright et al., 1998). Although the organic component was higher in quadrat one, increased leaching of the A horizon pointed to the potential lack of retention and absorption by dominant trees, which may lead to less moisture availability due to the nature of a well drained soil. This lack of moisture availability may influence the overall structure of the plant community.

The occurrence of small-scale disturbances, which increase the volume of CWD in a forest, offers considerable regeneration potential for species such as western hemlock (Lertzman, 1992; Lorimer, 1984). This was apparent in our megaplot, where high amounts of fallen, decomposing trees and CWD had a direct relationship with the growth of western hemlock seedlings. As suggested in other studies, germination of western hemlock is dominant in comparison with other tree species (mountain hemlock, subalpine fir, sitka spruce, western red cedar) on fallen logs and tip-up mounds found in gaps (Peterson et al., 1997; Lorimer, 1984). Quadrat one provided a clear example of this where we observed the growth of at least 209 seedlings on a single fallen veteran. More than 40 other western hemlock trees between the ages of 3 and 43 were counted in the same quadrat. In addition to 
the presence of CWD, the availability of abundant sunlight and water likely supported early stages of germination.

Time varies based on microsite conditions, but in pristine conditions, germination occurs approximately 2-3 years after a disturbance. The delayed germination within the megaplot could be attributed to the elevation and reduced growing season of the site. Western hemlock trees were dominant in the megaplot canopy and in the surrounding stand. Their dominance in the understory (area where shrubs and herbaceous plants grow) suggests that western hemlock species are particularly good at regenerating in areas with CWD. Although western hemlock demonstrates high seedling germination rates, significant consequences of elevated gap productivity were also observed in quadrat three.

Quadrat three presented a situation where gap formation led to an increased rate of regeneration that resulted in the subsequent mortality of juvenile western hemlock. It is thought that this was due to increased competition for limiting growth factors, such as sunlight and nutrients. Likely the gap in quadrat three was highly productive in the early stages of its formation when sunlight was abundant and CWD nursing logs were moderately decomposed. This is evident by the dense network of similarly aged western hemlock in the stand growing on decaying remnants of CWD. High volumes of CWD lead to greater concentrations of nutrients in the soil and higher moisture retention. These conditions are ideal for species recruitment (Siitonen et al., 2000).

This evidence supports our hypothesis that most trees in quadrat three germinated during favorable conditions following a small-scale disturbance. This is due to the higher overall species richness and productivity, as well as the availability of nutrients in what would have been the newly formed gap approximately 30 years ago. This response is typical in gap formations of the ICH, known for its dense forest canopy and shade tolerant plant communities (Wright et al., 1998). Also evident in quadrat three is the transition away from a gap phase as the stand matures, out-competed species die, and dominant and sub-dominant trees take hold. This quadrat exemplifies successional gap dynamics and the transition that occurs when light and nutrients are limiting factors in a stand.

\section{Conclusion}

New forest gaps support increased species richness and productivity in ICH forests of Glacier National Park. This study demonstrates the temporal succession of gaps in their early, intermediate, and late stages. Good growth conditions resulting from small-scale disturbances increase productivity, which over time can lead to increased stand density and higher intra- and inter- species competition resulting in 
mortality. In Glacier National Park, newly formed gaps have higher species percent cover and richness in all vegetation layers in comparison to intermediate gaps that have dramatically reduced percent cover and richness as they progress into an intermediate age class. Germination of western hemlock trees was most successful when CWD was present in decay class three or greater. This study is consistent with mensuration studies completed in the ICH of the Columbia Mountains and in northern British Columbia examining frequency of canopy gap formations due to small-scale disturbances in mature, species-diverse forests. Small-scale disturbances play a key role in determining the distribution and abundance of species in a forest.

\section{Future Research}

As we learn more about ecological disturbances it is clear that more research needs to be completed in order to understand how forests will respond to future climatic conditions. Research is needed in Glacier National Park to understand the interactions of natural and anthropogenic disturbances, as well as how small- and large- scale disturbances interact within the landscape. Future work could include a more detailed comparison study of multiple megaplots distributed throughout the $\mathrm{ICH}$ zone of the Park. This research could focus on the changing extent of ICH forests in Glacier National Park as warming climate conditions extend the elevation of the ICH, creating a larger transitional area between ICH and ESSF zones. It is predicted that a warming climate will create greater incidences of species overlap and hybridization between the ICH and ESSF designations.

\section{References}

Acevedo, M.F., Urban, D.L. \& Ablan, M. (1995). Transition and gap models of forest dynamics. Ecological Applications, 5(4), 1040-1055

Bartemucci, P., Coates, K.D., Harper, K.A. \& Wright, E.F. (2002). Gap disturbances in northern old growth forests of British Columbia, Canada. Journal of Vegetation Science, 13(5), 685-696. doi:10.1111/j.16541103.2002.tb02096.x

BEC field Manual. (1998). Field manual for describing terrestrial ecosystems. BC Ministry of Environment, BC Ministry of Forests, Victoria, British Columbia: Resources industry branch, (pp.8-12, 24-32).

BECWeb. (2011). Interior Cedar-Hemlock forests in Southeastern British Columbia. Retrieved from http://www.for.gov.bc.ca/hre/becweb/

Bleiker, K.P, Lindgren, B.S., \& Maclauchlan, L.E. (2003). Characteristics of subalpine fir susceptible to attack by western balsam bark beetle (coleoptera: 
Scolytidae). Canadian Journal of Forest Research, 33(8), 1538-1538. doi:10.1139/x03-071

Clark, D \& Clark, D. (1992). Life-history diversity of canopy and emergent trees in neo-tropical rain-forest. Ecological Monographs, 62(3), 315-244.

Coates, D.K. (2000). Conifer seedling response to northern temperate forest gaps. Forest Ecology and Management, 127, 249-269.

Coates. D.K. (2002). Tree recruitment in gaps of various size, clearcuts and undisturbed mixed forest of interior British Columbia, Canada. Forest Ecology and Management, 155, 387-398.

Downs, A. (Eds.). (1980). Incredible Rogers Pass. Surrey, British Columbia: Frontier Books,(pp. 14-34).

Duncan, R., Buckley, H., Urlich, S., Stewart, G., \& Geritzlehner, J. (1998). Smallscale species richness in forest canopy gaps: The role of niche limitation versus the size of the species pool. Journal of Vegetation Science, 9(3), 455460. doi: $10.2307 / 3237109$

Gray, A.N. \& Spies, T.A. (1997). Microsite controls on tree seedling establishment in conifer forest canopy gaps. Ecology, 78(8), 2458-2473. doi:10.1890/00129658

Gutsell, S.L. \& Johnson, E.A. (2002). Accurately aging trees and examining their height-growth rates: implications for examining forest dynamics. Journal of Ecology, 90, 153-166.

Johnson, E., Fryer, G., \& Heathcott, M. (1990). The influence of man and climate on frequency of fire in the Interior wets belt forest, British Columbia. Journal of Ecology, 78(2), 403-412.

Ketcheson, M. V., Braumandl, T. F., Meidinger, D., Utzig, G., Demarchi, D. A. \& Wikeem, B. (1991). Chapter 11: Interior Cedar-Hemlock zone. In D. Meidinger and J. Pojar (Eds.), BC Ministry of Forests, Ecosystems of British Columbia, 167-181. Victoria, Canada: Research Branch. Retrieved from http://www.for.gov.bc.ca/hfd/pubs/docs/srs/srs06/chap11.pdf

Krebs, C.J. (1999). Ecological methodology. Menlo Park, California: Benjamin/Cummings (pp. 39-40).

Lertzman, K.P. (1992). Patterns of gap-phase replacement in a subalpine, oldgrowth forest. Ecology, 73(2), 657-669.

Lorimer, C. (1984). Methodological considerations in the analysis of forest disturbance history. Canadian Journal of Forest Research. 15, 200-213.

McCarthy, J. (2001). Gap dynamics of forest trees: A review with particular attention to boreal forests. Environmental Reviews, 9(1), 1-1. doi:10.1139/er9-1-1 
McCleave, J.M. (2008). Chapter 7: Mount Revelstoke and Glacier National Parks. The regional integration of protected areas: a study of Canada's national parks. Unpublished $\mathrm{PhD}$ dissertation. University of Waterloo, Waterloo, Ontario, (pp. 198-229).

McCloskey, S., Daniels, L. \& McLean, J. (2009). Potential impacts of climate change on western hemlock looper outbreaks. Northwest Science, 83(3), 225-238.

McGrew, J.C., \& Monroe, C.B. (2000). An introduction to statistical problem solving in Geography. United States of America: The McGraw-Hill Companies, Inc.

Parish, R., Lloyd, D., Coupé, R., \& Antos, J. (1996). Plants of southern interior British Columbia. Vancouver: Lone Pine Pub.

Parks Canada. (2009). Glacier National Park of Canada: Old growth inland forest. Retrieved from: http://www.pc.gc.ca/pn-np/bc/glacier/natcul/natcul1/c.aspx

Parks Canada. (2009b). Teacher Resource Centre: Glacier National Park of Canada.Retrieved from: http://www.pc.gc.ca/apprendre-learn/prof/itm2-crptrc/htm/fglacier_e.asp

Parks Canada. (2011). Glacier National Park of Canada - Weather and Climate. Retrieved from: http://www.pc.gc.ca/pn-np/bc/glacier/visit/visit4.aspx

Peterson, E.B., Peterson, N.M, Weetman, G.F, \& Martin, P.J. (1997). Ecology and management of sitka spruce: emphasizing its natural range in British Columbia.Vancouver, British Columbia: UBC Press, (pp. 80-81).

Pojar, J., MacKinnon, A. \& Coupe, P.B. (2008). Plants of Coastal British Columbia, including Washington, Oregon \& Alaska. Edmonton, Alta: Lone Pine Pub.

Roush, W. (2007). A substantial upward shift of the alpine treeline ecotone in the southern Canadian Rocky Mountains. MSc Thesis: University of Victoria, (pp. 34-75).

Runkle, J.R. (1992). Guidelines and sample protocol for sampling forest gaps. No. 283.Portland, Or: U.S.D.A. Forest Service, Pacific Northwest Research Station.

Scharenbroch, B.C. \& Bockheim, J.G. (2007). Impacts of forest gaps on soil properties and processes in old growth northern hardwood-hemlock forests. Plant and Soil, 294(1), 219-233. doi:10.1007/s11104-007-9248-y

Sherman, R.E., Fahey, T.J, \& Battles, J.J. (2000). Small scale disturbance and regeneration dynamics in a neotropical mangrove forest. Journal of Ecology, 88(1), 165-168. 
Siitonen, J., Martikainen, P., Punttila, P. \& Rauh, J. (2000). Coarse woody debris and stand characteristics in mature managed and old-growth boreal mesic forests in southern Finland. Forest ecology and management, 128, 211-225.

Spies, T., Franklin, J. \& Klopsch, M. (1990). Canopy gaps in douglas-fir forests of the Cascade Mountains. Canadian Journal of Forest Research, 20(5), 649658. doi: $10.1139 / \times 90-087$

Speers, J.H. (2010). Fundamentals of tree ring research. Tucson, USA: The University ofArizona Press, (pp. 192-194).

Stokes, M.A. \& Smiley, T.L. (1964). An Introduction to Tree-Ring Dating. Chicago, USA: University of Chicago Press, (pp. 69-73).

Wright, E.F., Canham, C.D. \& Coates, K.D. (2000). Effects of suppression and release on sapling growth for 11 tree species of northern, interior British Columbia. Canadian Journal of Forest Research, 5(1), 197-202.

Yamamoto, S. (2000). Forest gap dynamics and tree regeneration. Journal of Forest Research, 5(4), 223-229. doi:10.1007/BF02767114

\section{Contact Information}

Kira Michelle Hoffman, from the Department of Geography, can be reached at kiramhoffman@gmail.com.

Carley Coccola, from the Department of Geography, can be reached at carleycoccola@gmail.com.

Kimberly House, from the Department of Geography, can be reached at kimhouse8@gmail.com.

Annie Markvoort, from the Department of Geography, can be reached at amarkvoort@gmail.com.

\section{Acknowledgments}

We would like to thank Dr. Dan Smith and Dr. Jim Gardner for an amazing educational experience throughout the 477 geography field school. We would also like to thank our teaching assistants Kara Pitman, Jodi Axelson and Bethany Coulthard for all their assistance in the field and in the UVic Tree Ring Lab. 